\title{
Antisurvivin oligonucleotides inhibit growth and induce apoptosis in human medullary thyroid carcinoma cells
}

\author{
Zhen-Xian $\mathrm{Du}^{1,5_{*}}$, Hai-Yan Zhang ${ }^{1,5_{*}}$, \\ Da-Xin Gao ${ }^{2}$, Hua-Qin Wang ${ }^{3}$, \\ Yong-Jun $\mathrm{Li}^{4}$ and Guo-Liang $\mathrm{Liu}^{1}$ \\ ${ }^{1}$ Department of Endocrinology and Metabolism \\ The First Affiliated Hospital, China Medical University \\ Shenyang 110001, P.R. China \\ ${ }^{2}$ Department of Orthopedics \\ The First Municipal Hospital of Qinhuangdao \\ Qinhuangdao 066000, P.R. China \\ ${ }^{3}$ Department of Neurology \\ Kyoto University Graduate School of Medicine \\ Kyoto 606-8507, Japan \\ ${ }^{4}$ Department of Experimental Pathology \\ China Medical University \\ Shenyang 110001, P.R. China \\ ${ }^{5}$ Corresponding author: Tel, 86-24-23926176; \\ Fax, 86-24-23926176; E-mail, dzx_doctor@hotmail.com \\ *These authors contributed equally to this work.
}

\section{Accepted 9 May 2006}

Abbreviations: AO/EB, acridine orange/ethidium bromide; ASODNs, antisurvivin oligonucleotides; CODNs, control oligonucleotides; CT, calcitonin; IAP, inhibitor of apoptosis protein; IC50, 50\% inhibiting concentration; MTC, medullary thyroid carcinoma; MTT, 3-(4,5dimethylthiazol-2-yl)-2,5-diphenyltetrazolium bromide; NT, normal thyroid; ODNs, oligonucleotides; RT-PCR, reverse transcriptionPCR; TC, Thyroid carcinoma

\begin{abstract}
Suvivin is a novel member of the inhibitor of apoptosis protein (IAP) family, which is known to be over-expressed in various carcinomas and associated with their biologically aggressive characteristics. The aim of this study was to investigate survivin expression in human medullary thyroid carcinoma (MTC) and a MTC cell line TT, correlate suvivin expression with clinicopathologic features of MTC, and test effects of antisurvivin oligonucleotides (ASODNs) on growth and apoptosis of TT cells. Survivin expression was immunohistochemically determined in formalin-fixed and paraffinembedded specimens obtained from 10 cases of normal thyroid (NT) and 10 cases of MTC, and in TT cells. In TT cells, we confirmed survivin expression
\end{abstract}

and its down-regulation by ASODNs using RT-PCR and Western blot analyses, and investigated effects of ASODNs on viability and growth by MTT assay and apoptosis by apoptotic analyses including DNA laddering assay, acridine orange/ethidium bromide staining and flow cytometric cell cycle analysis. Immunohistochemical analysis showed high survivin expression in MTC and TT cells, whereas no immunoreactivity was detectable in NT. Statistical analyses revealed no significant correlation of survivin expression with the clinicopathologic features of MTC. In TT cells, survivin expression at both mRNA and protein levels was confirmed and could be down-regulated by ASODNs concomitant with decrease in viability and growth, and increase in apoptosis. Our results suggest that survivin plays an important role in MTC independent of the conventional clinicopathologic factors, and ASODNs is a promising survivin- targeted gene therapy for MTC.

Keywords: apoptosis; inhibitor of apoptosis proteins; oligonucleotides, antisense; survivin protein, human; thyroid neoplasms

\section{Introduction}

Suvivin is a novel member of the inhibitor of apoptosis protein (IAP) family, whose gene is located at chromosome $17 q 25$. Survivin is reported to inhibit apoptosis triggered by various inducers such as Fas-Fas ligand pathway, caspase cascades, and chemotherapy (Ambrosini et al., 1997; LaCasse et al., 1998; Tamm et al., 1998; Li \& Altieri, 1999). Survivin is thought to help cells overcome the G2/M checkpoint against apoptosis due to its expression in the G2-M phase of the cell cycle and interaction with microtubules of the mitotic spindle (Li et al., 1998).

Highly expressed survivin has been found in a growing number of carcinomas, such as colorectal adenocarcinoma, esophageal carcinoma, non-small cell lung carcinoma, pancreatic cancer, and melanoma, and demonstrated to be associated with biologically aggressive characteristics including unfavorable prognosis in some tumors (Kawasaki et al., 1998; Kato et al., 2001; Kren et al., 2004; Abd El-Hameed, 2005; Lee et al., 2005; Shinohara et al., 2005; Takeuchi et al., 2005). In addition, the high 
prevalence of survivin is also found in the premalignant lesions of skin carcinoma and uterine carcinoma (Grossman et al., 1999; Kim et al., 2002). But it is not usually present in normal tissues and rarely found in mature tissues (Ambrosini et al., 1997; Zaffaroni et al., 2005). These findings suggest that survivin may be potentially important in the development and/or progression of carcinomas.

Thyroid carcinoma (TC) is a representative malignancy originating from the endocrine organs. Thereinto, medullary thyroid carcinoma (MTC) is an aggressive tumor arising from neoplastic thyroid parafollicular C cells, accounting for $3-5 \%$ of all thyroid malignancies (Ball et al., 2001). So far, in thyroid tumors, information on survivin overexpression is available in lymphoma and thyroid neoplasms including follicular adenoma, and follicular and papillary and anaplastic carcinomas (Sugawara et al., 2002; Ito et al., 2003), but little in MTC. Moreover, in those thyroid neoplasms, Ito et al. (2003) found a significant relationship of the survivin expression with dedifferentiation, i.e. the anaplastic transformation of tumor cells, suggesting that survivin may be a potential target for anti-TC gene therapy.

In this study, we immunohistochemically examined survivin expression in human normal thyroid tissues, MTC, and a human MTC cell line, TT. Furthermore, in MTC, the correlations were analyzed between survivin expression and the clinicopathologic features including gender, age, tumor size, T stage, lymph node invasion, distant metastasis and TNM stage; in TT cells, survivin expression was confirmed by RT-PCR and Western blot analyses, and effects of antisurvivin oligonucleotides (ASODNs) on survivin expression, growth and viability, and apoptosis were investigated.

\section{Materials and Methods}

\section{Clinical samples}

Paraffin-embedded tissue samples of human normal thyroid (NT, $n=10$ ) and medullary thyroid carcinoma (MTC, $n=10$ ) were retrieved from storage at the Department of Pathology, China Medical University, China. The project was approved by the ethics committees of the hospital and informed consent was obtained from the patients or their first-degree relatives. The ten NT tissue samples had been obtained by autopsy. The other MTC samples were resected surgically between 1999 and 2003. The diagnoses for NT and MTC were confirmed histologically. Moreover, MTC was confirmed by the tumor marker calcitonin (CT) immunostaining. The autopsy specimens were obtained from cadavers of people with a mean age of $38 \pm 12$ years (range 20-54). The mean age with SD for the MTC patients was $43 \pm 16$ years (range 23-71). No patients had undergone preoperative radiotherapy or chemotherapy. Information regarding the clinicopathologic features of the 10 MTC patients, such as gender, age, tumor size, capsule invasion, adjacent organ involvement, lymph node invasion and distant metastasis at the time of surgery, was available. Based on these information, TNM staging for each tumor was reevaluated according to the TNM classification system recommended by the American Joint Committee on Cancer (AJCC) in 2002 (Greene et al., 2002).

\section{Cell line and cell culture}

The human MTC cell line TT was obtained from Chinese Center for Typical Culture Collection. The cells were maintained in F12 culture medium (Gibco Co.) supplemented with $10 \% \mathrm{FCS}$ at $37^{\circ} \mathrm{C}$ in a $5 \%$ $\mathrm{CO}_{2}$ humidified atmosphere, fed every 3 days with complete medium, and subcultured when confluence was reached.

\section{Immunohistochemical analyses of clinical samples and TT cell line}

For clinical samples, four- $\mu$ m-thick paraffin sections were serially cut from paraffin-embedded tissues and deparaffinized following being mounted on slides. For TT cell line, cells $\left(1 \times 10^{5}\right.$ cells/well $)$ were grown on 4-well chamber glass slides in complete F12 medium; the slides at $80-90 \%$ confluence were rinsed in PBS, dried well, and then fixed in $95 \%$ ethanol for $4 \mathrm{~h}$ at $4{ }^{\circ} \mathrm{C}$. All slides were treated for three 5-minute cycles in a microwave oven at $500 \mathrm{~W}$ using $0.01 \mathrm{M} \mathrm{pH} 6.0$ citrate buffer to unmask the antigens. Slides were then immersed in methanol containing $3 \%$ hydrogen peroxide for 5 min to block endogenous peroxidase activity. For immunohistochemical detection of survivin or CT, slides were incubated in a humid chamber overnight at $4^{\circ} \mathrm{C}$ with $1: 100$ dilution of rabbit anti-human survivin monoclonal (Boster Biotechnology Co., Wuhan, China) or rabbit anti-human CT polyclonal (Maixin Biological Technology Co., Fuzhou, China) antibody. Bound antibodies were visualized using a SABC complex kit (Boster Biotechnology Co., Wuhan, China), which is based on streptavidin-biotin-peroxidase complex-binding technique, according to the manufacture's instruction. Diaminobenzidine was used as the chromogen. After the expected stain intensity developed, sections were lightly counterstained with hematoxylin. As negative controls, immunostaining was performed by incubating samples with PBS instead of the primary antibody. 


\section{Immunohistochemical evaluation}

Cells were regarded as positive for survivin when immunoreactivity was clearly observed in their cytoplasms or nuclei. The immunohistochemical results with no positive cells were considered as negative, and those with positive cells as positive.

\section{Treatment of $T T$ cells with antisurvivin and control oligonucleotides}

20-mer antisense oligonucleotides (ODNs) targeting human survivin mRNA was used as antisurvivin oligonucleotides (ASODNs) (Xia et al., 2002). The reverse sequence of ASODNs was used as control ODNs (CODNs). The sequences of ODNs were 5'-CCCAGCCTTCCAGCTCCTTG-3' (ASODNs) and 5'-GTTCCTCGACCTTCCGACCC-3' (CODNs). The ASODNs and CODNs were synthesized in the form of phosphorothioate oligonucleotides by Sangon Biotechnology Inc. (Shanghai, China), and employed for transfections in TT cells. One day before transfection, TT cells $\left(2 \times 10^{5}\right.$ cells/well $)$ were plated in 12 -well tissue culture plates. Cells were rinsed with $2 \mathrm{ml}$ of serum-free F12 medium before transfection. ODNs were delivered in the form of complexes with Lipofectin (Life Technologies, Inc.) according to the manufacturer's instructions. Briefly, ASODNs or CODNs and Lipofectin reagent at a charge ratio of $1: 2$ were aggregated for $15 \mathrm{~min}$ at room temperature. The prerinsed cells were treated with the above ODNs-Lipofectin mixture in serum-free F12 medium at a final ODNs concentration of 200-800 $\mathrm{nM}$. After incubation for $24 \mathrm{~h}$, the treating culture medium was replaced with fresh F12 medium, and cells were cultured for an additional $6 \mathrm{~h}$ or longer. Untreated cells, Lipofectin-treated cells and CODNstreated cells were used as control groups in all experiments.

\section{RT-PCR analysis of survivin expression in $\mathrm{TT}$ cells}

For reverse transcription-polymerase chain reaction (RT-PCR) analysis, total RNA was extracted from cell cultures using Trizol reagents according to the manufacturer's recommendations (Life Technologies, Inc.), the quality and quantity of RNA were assessed at the absorbance 260/280 using a UV spectrophotometer (UV-310, Spectronic, UK), and all samples showed absorbency ratios ranging between 1.8 and 2.0. RT-PCR procedures were based on the manufacturer's instructions using a RT-PCR kit (AMV 2.1) (TakaRa Biotechnology Co., Ltd). Using 5 $\mu \mathrm{g}$ total RNA, cDNAs were synthesized by RT and taken for PCR amplification. RT-PCR primers were ordered from Life Technologies. The primer sequences were 5'-ATGGGTGCCCCGACGTTG-3' (sense) and 5'-AGAGGCCTCAATCCATGG-3' (antisense) for survivin and 5'-ATCATGTTTGAGACCTTCAACA-3' (sense) and 5'-CATCTCTTGGTCGAAGTCCA-3' (antisense) for $\beta$-actin used as internal control. Expected RT-PCR product sizes were $436 \mathrm{bp}$ for survivin and $308 \mathrm{bp}$ for $\beta$-actin. PCR conditions comprised a predenaturation for $2 \mathrm{~min}$ at $94^{\circ} \mathrm{C}$, followed by 35 cycles of denaturation for $1 \mathrm{~min}$ at $94^{\circ} \mathrm{C}$, annealing for $30 \mathrm{~s}$ at $60^{\circ} \mathrm{C}$, and extension for $1 \mathrm{~min}$ at $72^{\circ} \mathrm{C}$. The PCR products were separated by electrophoresis on a $2 \%$ agarose gel. Gels were stained with ethidium bromide, destained, and photographed by the image analysis system Chemilmager 5500 (Alpha Innotech). The relative mRNA expression for each sample was calculated as the ratio of the integrated $O D$ of survivin and that of $\beta$-actin using the image software MetaMorph 5.0 (UIC). It was then normalized to that in untreated cell group taken as $100 \%$.

\section{Western Blotting analysis of survivin expression in TT cells}

Cells were washed twice with ice-cold PBS, and lysed with $300 \mu \mathrm{l}$ of lysis buffer solution $(50 \mathrm{mM}$ Tris- $\mathrm{HCl}, \mathrm{pH} 7.4 ; 0.15 \mathrm{M} \mathrm{NaCl} ; 1 \%$ Triton $\mathrm{X}-100$, and $1 \mathrm{mM}$ EDTA) containing a complete protease inhibitor cocktail. The lysate was sonicated six times for duration of $1 \mathrm{~s}$, laid on ice for $15 \mathrm{~min}$, and then centrifuged for $15 \mathrm{~min}$ at $15,000 \mathrm{rpm}$. The supernatants were stored at $-20^{\circ} \mathrm{C}$ until use. The concentration of protein in the supernatant was measured by the bicinchoninic acid protein assay reagent (Pierce Chemical Co., Rockford, IL) according to the manufacturer's suggestions. Equal amounts $(40 \mu \mathrm{g})$ of proteins were electrophoresed through a $12 \%$ sodium dodecyl sulfate polyacrylamide gel (SDSPAGE) and transferred onto nitrocellulose membranes (Amersham International plc, Amersham, Bucks, UK). Membranes were blocked with 5\% non-fat milk for $30 \mathrm{~min}$ at room temperature. They were then incubated with a rabbit anti-human monoclonal antibody to survivin (Boster Biotechnology Co., Ltd) overnight at $4^{\circ} \mathrm{C}$. Bound antibodies were revealed with a horseradish peroxidase-conjugated goat anti-rabbit IgG (Pierce Chemical Co.). The immunological complexes were visualized by reagents (ECL; Amersham Pharmacia Biotech, Freiburg, Germany). Each sample was also probed with an anti- $\beta$-actin antibody (Sigma-Aldrich Corp.) as loading control. Membranes were scanned using the Chemilmager 5500. The relative protein expression for each sample was calculated as the ratio of the integrated OD of survivin and that of $\beta$-actin using the MetaMorph 5.0. It was then normalized to that in untreated cell group taken as $100 \%$. 


\section{MTT assay for the effect of ASODNs on viability and growth of TT cells}

For 3-(4,5-dimethylthiazol-2-yl)-2,5-diphenyltetrazolium bromide (MTT) assay, TT cells were seeded in 12-well plates at a density designed to reach $70-80 \%$ confluence at the time of assay. The cells were then rinsed with F12 medium before transfection and treated with different concentrations of ASODNs (200-800 nM) starting on the 2 nd day. After $24 \mathrm{~h}$ of treatment, $20 \mu \mathrm{l}$ of $5 \mathrm{mg} / \mathrm{ml}$ MTT (Sigma, USA) was added to each well of cells, and the plate was incubated for $4 \mathrm{~h}$ at $37^{\circ} \mathrm{C}$. The medium was removed, and the MTT crystals were solubilized in DMSO (Sigma) and subjected to centrifugation to pellet the cellular debris. Spectrophotometric absorbance of each sample was measured at $490 \mathrm{~nm}$ by an enzyme-linked immunosorbent assay reader (DG-3022A) using Ascent software (version 2.4). The percentage of viable cells was expressed as a percentage of the control average absorbance values obtained with untreated cells, and then normalized to that in untreated cell group taken as $100 \%$.

\section{Apoptotic analysis of TT cells}

Three apoptotic assays were performed as below. (a) DNA laddering assay: Cells $\left(1 \times 10^{6}\right)$ were harvested via centrifugation and incubated at $50^{\circ} \mathrm{C}$ overnight in a $100 \mu$ l of lysis buffer $[100 \mathrm{mM} \mathrm{NaCl}$, $100 \mathrm{mM}$ Tris-HCl (pH 8.0), $20 \mathrm{mM}$ EDTA, 0.8\% SDS, and $100 \mu \mathrm{g} / \mathrm{ml}$ proteinase $\mathrm{K}]$. The samples were then treated with $20 \mathrm{mg} / \mathrm{ml}$ RNase for $1 \mathrm{~h}$ at $37^{\circ} \mathrm{C}$, and precipitated with $0.5 \mathrm{~mol} / \mathrm{L} \mathrm{NaCl}$ and equivalent volume of isopropanol. After centrifugation at 16,000 $\times g$ for 15 min and rinsing with $70 \%$ ethanol, the pellets were dissolved in $10 \mathrm{mM}$ Tris- $\mathrm{HCl}(\mathrm{pH}$ 8.0) and $1 \mathrm{mM}$ EDTA. The DNA concentration was estimated by measuring the absorbance at $260 \mathrm{~nm}$. DNA $(5 \mu \mathrm{g} / \mathrm{lane})$ were electrophoresed on $1.5 \%$
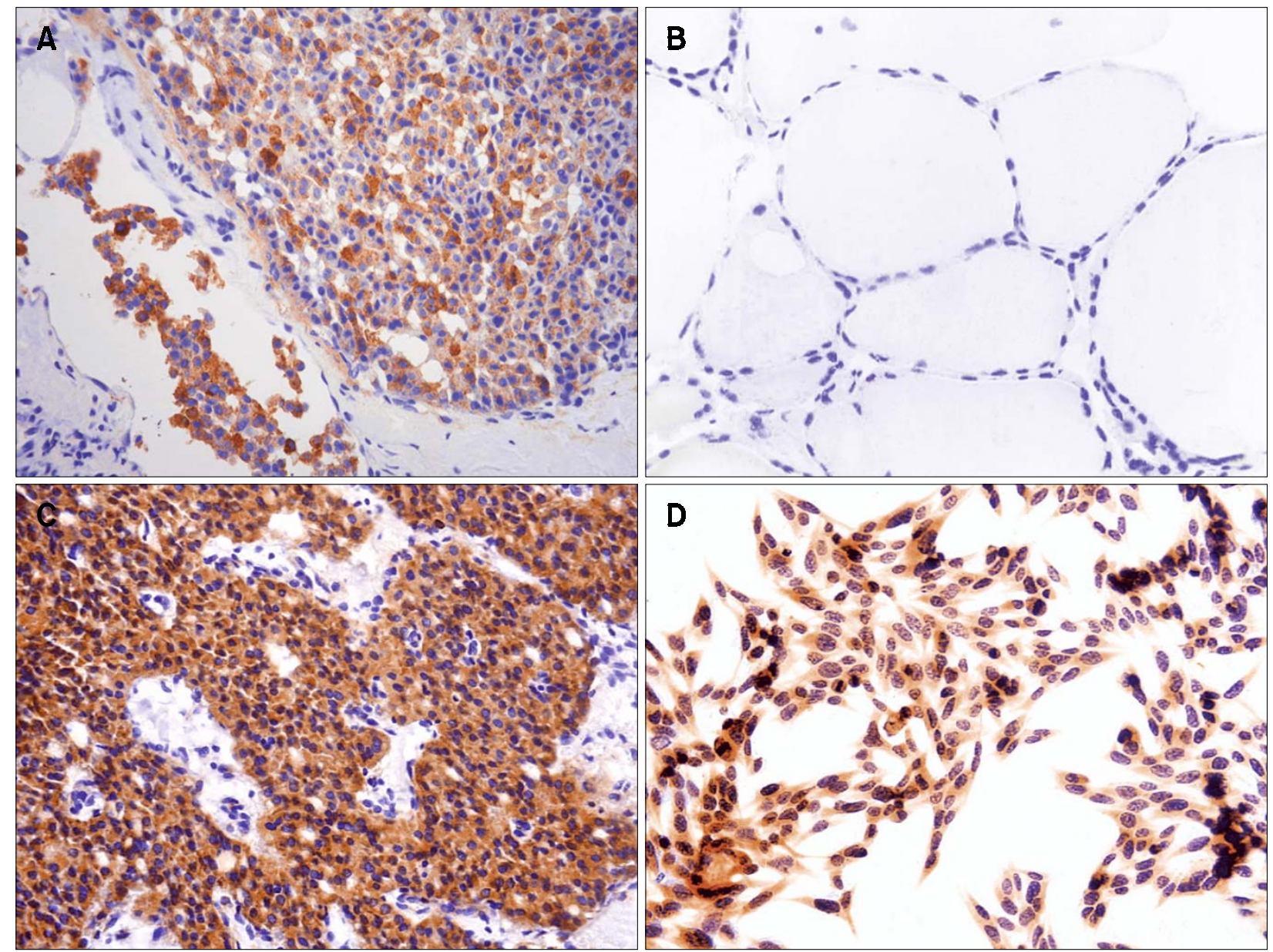

Figure 1. Immunohistochemical detection of calcitonin and suvivin expression. (A) Calcitonin expression was in MTC. (B-D) Survivin expression was in (B) normal thyroid, (C) MTC and (D) TT cells. Original magnification, $\times 400$. 
agarose gels. The gels were then stained with ethidium bromide, destained, and photographed under UV transillumination. (b) Acridine orange/ethidium bromide $(A O / E B)$ staining: Cells on the gelatincoated glass cover slips were prepared with different treatment as described above, fixed in $95 \%$ ethanol for $30 \mathrm{~min}$, and then pre-treated with $1 \%$ acetic acid for $30 \mathrm{~s}$ before exposure to $A O / E B$ dye mix (40 $\mu \mathrm{g} / \mathrm{ml}$ AO plus $100 \mu \mathrm{g} / \mathrm{ml} E B$ ) for $1 \mathrm{~min}$. The apoptotic cells were observed under fluorescence microscopy with the excitation wavelength at $415 \mathrm{~nm}$. (c) Flow cytometric cell cycle analysis: Cells were harvested by low-speed centrifugation, washed in PBS, fixed overnight in $70 \%(\mathrm{v} / \mathrm{v})$ cold ethanol at $4^{\circ} \mathrm{C}$, then washed in PBS, treated with $100 \mu \mathrm{g} / \mathrm{ml}$ RNase (Huamei Biotechnology Co., China) and stained with $10 \mu \mathrm{g} / \mathrm{ml}$ propidium iodide (PI) (Sigma) in the dark for $30 \mathrm{~min}$ at $4^{\circ} \mathrm{C}$. To obtain apoptosis index (AI), i.e. the percentage of apoptotic cells, flow cytometry was performed on a Becton Dickinson FACScan (Franklin Lakes, NJ), with acquisition and analysis of data performed using Becton Dickinson CELLQuest software. For each sample, at least $10^{4}$ cells were analyzed.

\section{Statistical analysis}

Each experiment was repeated three different times. Data are presented as means $\pm S D$, and analyzed with SPSS13.0. The concentration of ASODNs which inhibits $50 \%$ of survivin expression and cell proliferation (IC50) was determined by probit analysis. Fisher's exact test was employed to detect the correlations between the clinicopathologic features of MTC patients and survivin expression, and one-way ANOVA with Bonferroni's post hoc test was used as appropriate. A two-tailed $P<0.05$ was considered statistically significant.

\section{Results}

\section{Expression of survivin in NT, MTC and TT cells}

All specimens from MTC patients showed positive immunoreactivity for CT, a MTC marker (Figure 1A). In NT, MTC and TT cell line, survivin protein expression was immunohistochemically analyzed. The negative controls and NT manifested no immunoreactivity for suvivin, but MTC and TT cells showed its immunoreactivities in cytoplasms and nuclei (Figure 1B-D). The positive incidence of survivin protein immunoreactivity was $80 \%$ (8 of 10

Table 1. Clinicopathologic features of medullary thyroid carcinoma (MTC) patients and their correlations with survivin expression.

\begin{tabular}{|c|c|c|c|c|}
\hline \multirow{2}{*}{ Features } & \multirow{2}{*}{ Total, $n(\%)$} & \multicolumn{2}{|c|}{ Survivin immunoreactivity, $n(\%)$} & \multirow{2}{*}{$P$} \\
\hline & & Negative $(n=2)$ & Positive $(n=8)$ & \\
\hline \multicolumn{5}{|l|}{ Gender } \\
\hline Female & $6(60)$ & $1(50)$ & $5(63)$ & 1.000 \\
\hline Male & $4(40)$ & $1(50)$ & $3(37)$ & \\
\hline \multicolumn{5}{|l|}{ Age (yr) } \\
\hline$\leq 40$ & $5(50)$ & $1(50)$ & $4(50)$ & 1.000 \\
\hline$>40$ & $5(50)$ & $1(50)$ & $4(50)$ & \\
\hline \multicolumn{5}{|l|}{ Tumor size $(\mathrm{cm})$} \\
\hline$\leq 4$ & $5(50)$ & $1(50)$ & $4(50)$ & 1.000 \\
\hline$>4$ & $5(50)$ & $1(50)$ & $4(50)$ & \\
\hline \multicolumn{5}{|l|}{$\mathrm{T}$ stage } \\
\hline $1-2$ & $4(40)$ & $1(50)$ & $3(37)$ & 1.000 \\
\hline $3-4$ & $6(60)$ & $1(50)$ & $5(63)$ & \\
\hline \multicolumn{5}{|c|}{ Lymph node metastasis } \\
\hline Negative & $4(40)$ & $1(50)$ & $3(37)$ & 1.000 \\
\hline Positive & $6(60)$ & $1(50)$ & $5(63)$ & \\
\hline \multicolumn{5}{|l|}{ Distant metastasis } \\
\hline Negative & $9(90)$ & $2(100)$ & $7(88)$ & 1.000 \\
\hline Positive & $1(10)$ & $0(0)$ & $1(12)$ & \\
\hline \multicolumn{5}{|l|}{ TNM staging } \\
\hline$|-| \mid$ & $2(20)$ & $1(50)$ & $1(12)$ & 0.378 \\
\hline III-IV & $8(80)$ & $1(50)$ & $7(88)$ & 0.076 \\
\hline
\end{tabular}


samples) in MTC in contrast to the negative immunoreactivity in NT. We further screened TT cell line for survivin expression using RT-PCR and Western blot analyses. Expression of survivin in TT cells was detected at mRNA level by RT-PCR and confirmed at protein level by Western blot analysis.

\section{Clinicopathologic features of MTC patients and their relationships with survivin expression}

Clinicopathologic features of the MTC patients are presented in Table 1. There were 10 MTC patients (6 females, 4 males) with a median age of 41 years (range, 23-71; mean $\pm S D, 43 \pm 16$ ). The tumor size ranged between 1.3 and $10.1 \mathrm{~cm}$ (median, 4.1; mean $\pm S D, 4.6 \pm 2.8$ ). Tumors were classified as $\mathrm{T} 1, \mathrm{~T} 2, \mathrm{~T} 3, \mathrm{~T} 4 \mathrm{a}$, and T4b stages in $1(10 \%), 3$ $(30 \%), 1(10 \%), 4(40 \%)$, and $1(10 \%)$ cases respectively. Lymph node invasion were graded into N0, $\mathrm{N} 1 \mathrm{a}$, and N1b in $4(40 \%), 4(40 \%)$, and $2(20 \%)$ cases respectively. Distant metastasis was detected in $1(10 \%)$ patient. The TNM stages were I in 1 $(10 \%)$ patient, II in $1(10 \%)$, III in $2(20 \%)$, IVA in 4 $(40 \%)$, IVB in $1(10 \%)$, and IVC in $1(10 \%)$. No significant correlation was found between any of the above clinicopathologic features and survivin expression.

A
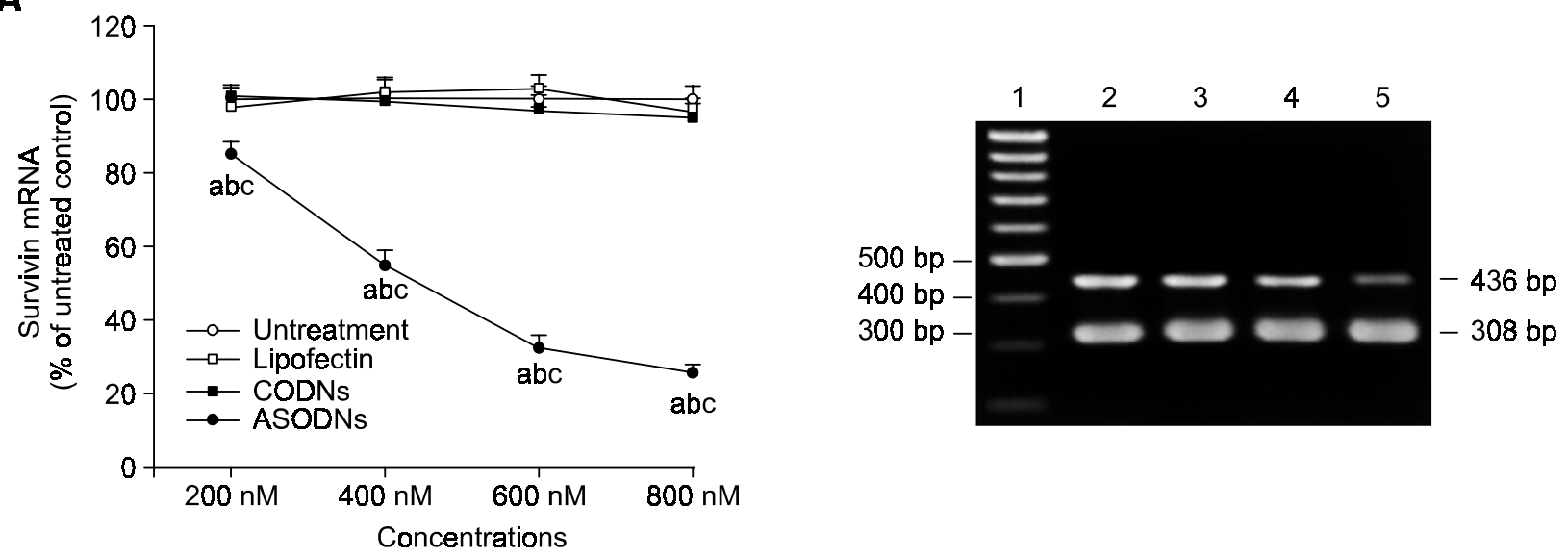

B
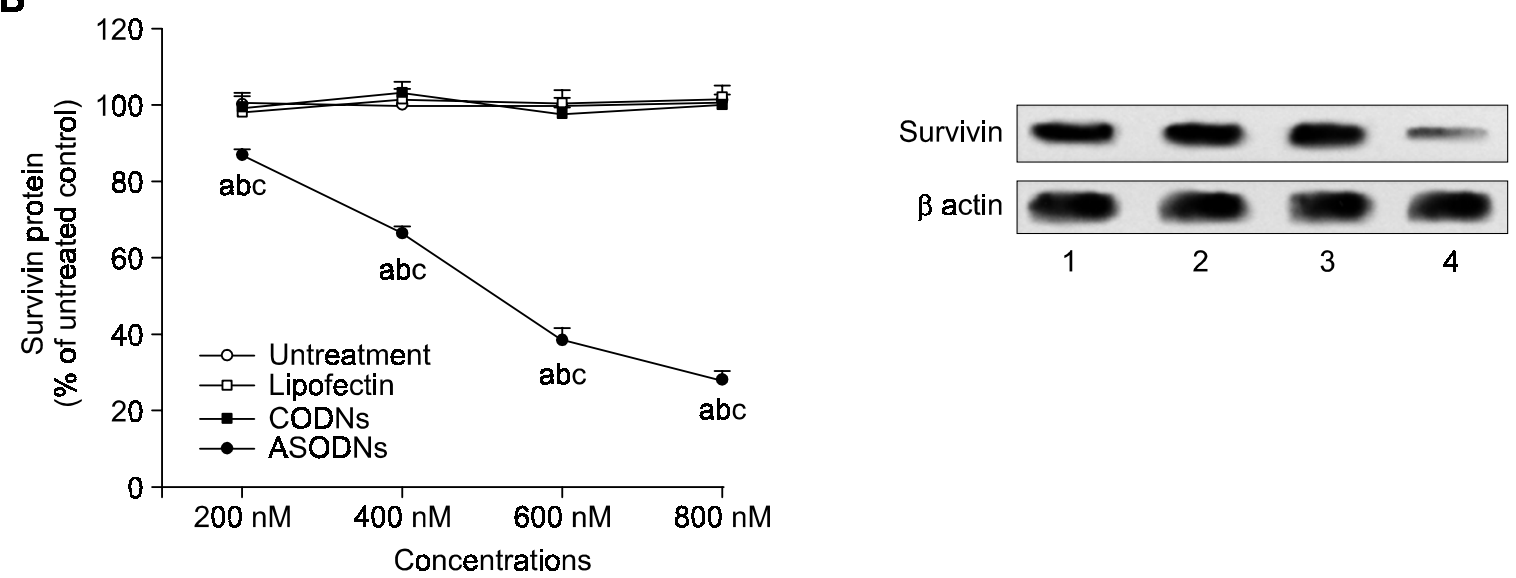

Figure 2. Down-regulation of survivin expression by ASODNs in TT cells. Cells were transfected for $24 \mathrm{~h}$ with 200-800 nM ASODNs followed by an additional 6 -h culture or longer in fresh F12 medium, and then harvested. Untreated cells, Lipofectin-treated cells, and CODNs-treated cells were used as controls. Data are normalized to those in untreated cell group which were taken as $100 \%$, and presented in graphs as means $\pm \operatorname{SD}(n=3$; ${ }^{\mathrm{a}} P<0.001$, vs untreatment group; ${ }^{\mathrm{b}} P<0.001$, vs Lipofectin group; ${ }^{\mathrm{C}} P<0.001$, vs CODNs group by one-way ANOVA with Bonferroni's post hoc test). (A) RT-PCR analysis of survivin mRNA. One representative result of RT-PCR was shown on the right. Lane 1: marker; Lane 2: untreatment; Lane 3: Lipofectin; Lane 4: $800 \mathrm{nM}$ CODNs; Lane 5: $800 \mathrm{nM}$ ASODNs. Normalized expression levels of survivin mRNA were graphed on the left. (B) Western blot analysis of survivin protein. Example of a Western blot analysis was shown on the right. 1: untreatment; 2: Lipofectin; 3: $800 \mathrm{nM}$ CODNs; 4: $800 \mathrm{nM}$ ASODNs. Normalized survivin protein levels were graphed on the left. 


\section{Down-regulation of survivin expression by ASODNs in $\pi$ cells}

To investigate the inhibitory effect of ASODNs on survivin expression, RT-PCR and Western blotting analyses were performed. No significant difference in survivin expression was found at both mRNA and protein levels between controls, i.e. untreated, Lipofectin-treated and CODNs-treated TT cells. However, as compared with controls, treatment with 200-800 nM ASODNs for $24 \mathrm{~h}$ significantly reduced survivin mRNA level by $15-75 \%$ with an IC50 of 494 $\mathrm{nM}$ and its protein level by $13-73 \%$ with an IC50 of $549 \mathrm{nM}$ in a dose-dependant manner at $30 \mathrm{~h}$ after

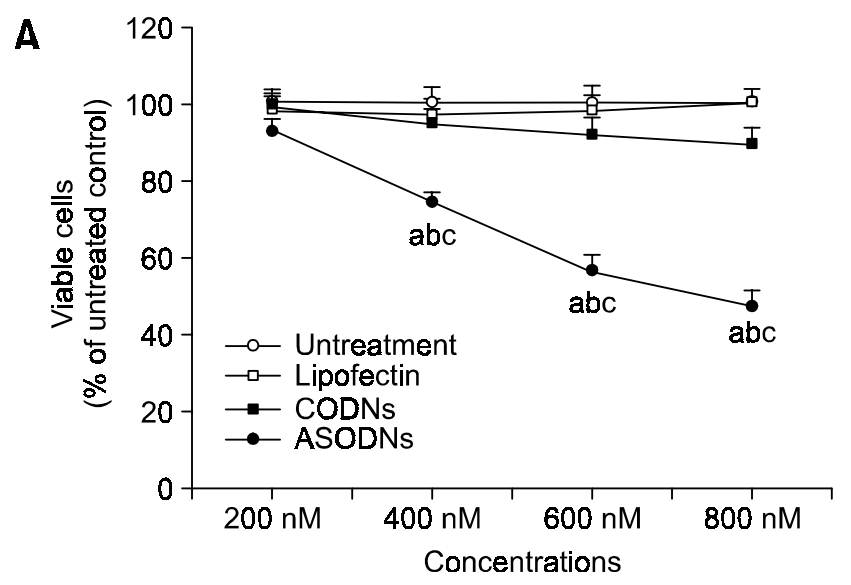

the start of transfection in TT cells (Figure 2).

\section{Inhibitory effects of ASODNs on viability and growth of $\pi$ cells}

As shown in Figure 3A, treatment of TT cells for $24 \mathrm{~h}$ with survivin ASODNs caused a dose-dependent decrease in cell viability and growth with an IC50 of $723 \mathrm{nM}$. The inhibition rates of cell proliferation exposed to $200 \mathrm{nM}, 400 \mathrm{nM}, 600 \mathrm{nM}$, and $800 \mathrm{nM}$ survivin ASODNs for $24 \mathrm{~h}$ were $8 \%, 26 \%, 43 \%$ and $53 \%$ at $30 \mathrm{~h}$ after the start of transfection, respectively. Furthermore, concentrations of $400-800$ $\mathrm{nM}$ were found to significantly inhibit viability and growth in ASODNs-treated cells compared to those in controls, whereas no significant inhibitory effect was observed between controls at any concentration. The dose-dependant death induced by ASODN could also be revealed by detachment of TT cells from the culture surface (Figure $3 \mathrm{~B}$ and $\mathrm{C}, \mathrm{D}, \mathrm{E}, \mathrm{F}$, $\mathrm{G) \text {. }}$
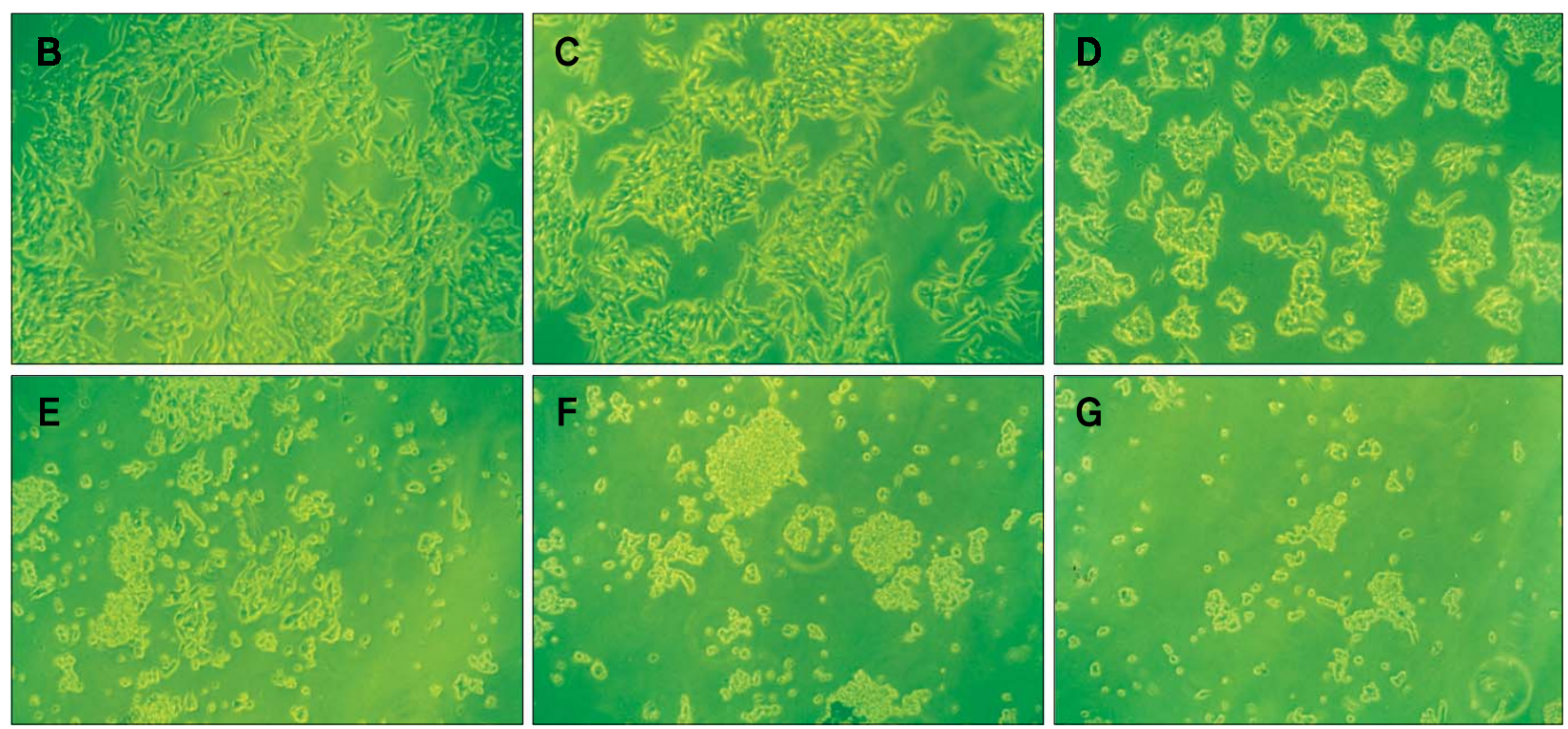

Figure 3. The effects of ASODNs on the viability and growth of TT cells. Following treatment for $24 \mathrm{~h}$ with an increasing concentration of ASODNs (200-800 nM), medium were replaced to F12 medium, and cells were cultured for an additional $6 \mathrm{~h}$. Photographs were then taken, and cell viability was determined by MTT assay. Untreated, Lipofectin-treated, and CODNs-treated cells were used as controls. (A) MTT assay for cell viability. Each value is normalized to that in untreated cell group which was taken as $100 \%$, and represents the mean \pm SD $\left({ }^{a} P<0.001\right.$, vs untreatment group; ${ }^{b} P<0.001$, vs Lipofectin group; ${ }^{\mathrm{C}} P<0.001$, vs CODNs group at the same concentration by one-way ANOVA with Bonferroni's post hoc test). (B-G) Photomicrographs of (B) untreated TT cells and TT cells treated with (C) $800 \mathrm{nM}$ CODNs, (D) $200 \mathrm{nM}$ ASODNs, (E) $400 \mathrm{nM}$ ASODNs, (F) 600 nM ASODNs, or (G) 800 nM ASODNs. Original magnification, $\times 200$. 


\section{Apoptotic induction by ASODNs in TT cells}

To verify the effect of ASODNs on apoptosis of TT cells, three different methods including DNA laddering assay, $A O / E B$ staining and flow cytometric cell cycle analysis, were adopted. DNA laddering assay showed detectable DNA ladders in ASODNstreated group, but not in controls (Figure 4A). AO/EB staining revealed apoptotic cells in ASODNs-treated group, but not in controls (Figure 4B). Flow cytometric cell cycle analysis found a significant dosedependant 1.8-11.1 fold increase in the apoptotic cell population in ASODNs-treated group relative to controls, with no noticeable apoptotic induction in controls (Figure 4C).

\section{Time course of inhibition of survivin expression by ASODNs in $T$ T cells}

Indeed in our study, survivin expression in TT cells has shown a progressively suppressed response to an increasing concentration of ASODNs (200-800 $\mathrm{nM}$ ) with a maximal depression by $800 \mathrm{nM}$ ASODNs. The time course of suvivin inhibition by $800 \mathrm{nM}$ ASODNs was then evaluated. Such experiments revealed an obvious inhibition of survivin by ASODNs at mRNA and protein levels starting within $12 \mathrm{~h}$ and persisting at least by $48 \mathrm{~h}$ after the start of transfection in ASODNs-treated group compared with controls (Figure 5). No significant difference was, however, found between controls in inhibition of survivin expression.
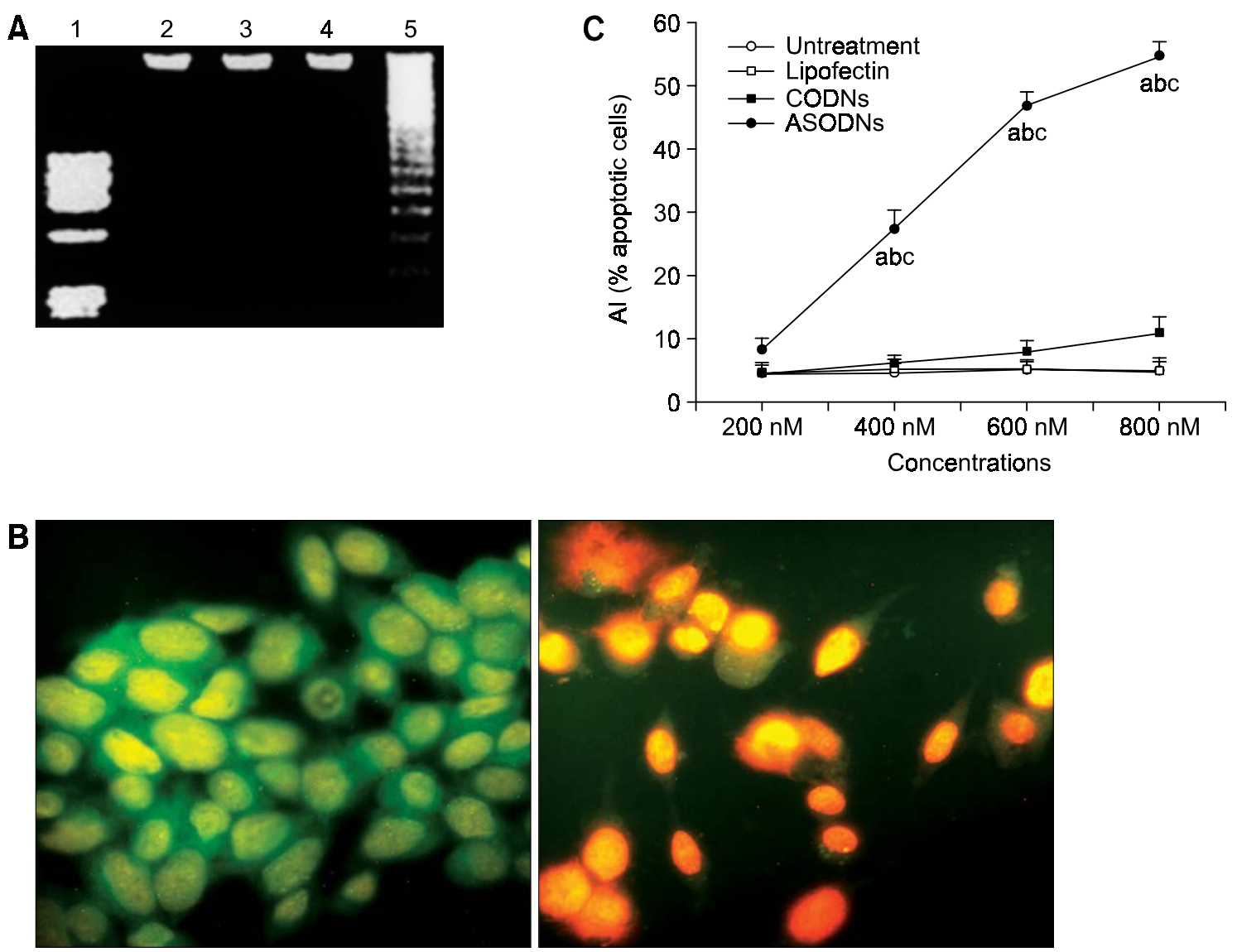

Figure 4. Apoptosis induction by ASODNs in TT cells. Cells are treated with 200-800 nM ASODNs for $24 \mathrm{~h}$ followed by an additional 6 -h culture with fresh F12 medium, and then collected for apoptotic analyses. Untreated, Lipofectin-treated, and CODNs-treated cells were used as controls. (A) Agarose gel electrophoresis for detecting DNA ladder. Lane 1: marker; Lane 2: untreatment; Lane 3: Lipfectin; Lane 4: CODNs; Lane 5: ASODNs. (B) AO/EB staining. Left: CODNs-treated cells; Right: ASODNs-treated cells. Cells with red or yellow-red nuclei indicate apoptotic cells (Original magnification, $\times 200$ ). (C) flow cytometric cell cycle analysis. Apoptotic indices were graphed. Data are expressed as means $\pm \operatorname{SD}\left(n=3,{ }^{a} P<0.001\right.$, vs untreatment group; ${ }^{b} P<0.001$, vs Lipofectin group; ${ }^{c} P<0.001$, vs CODNs group by one-way ANOVA with Bonferroni's post hoc test). 

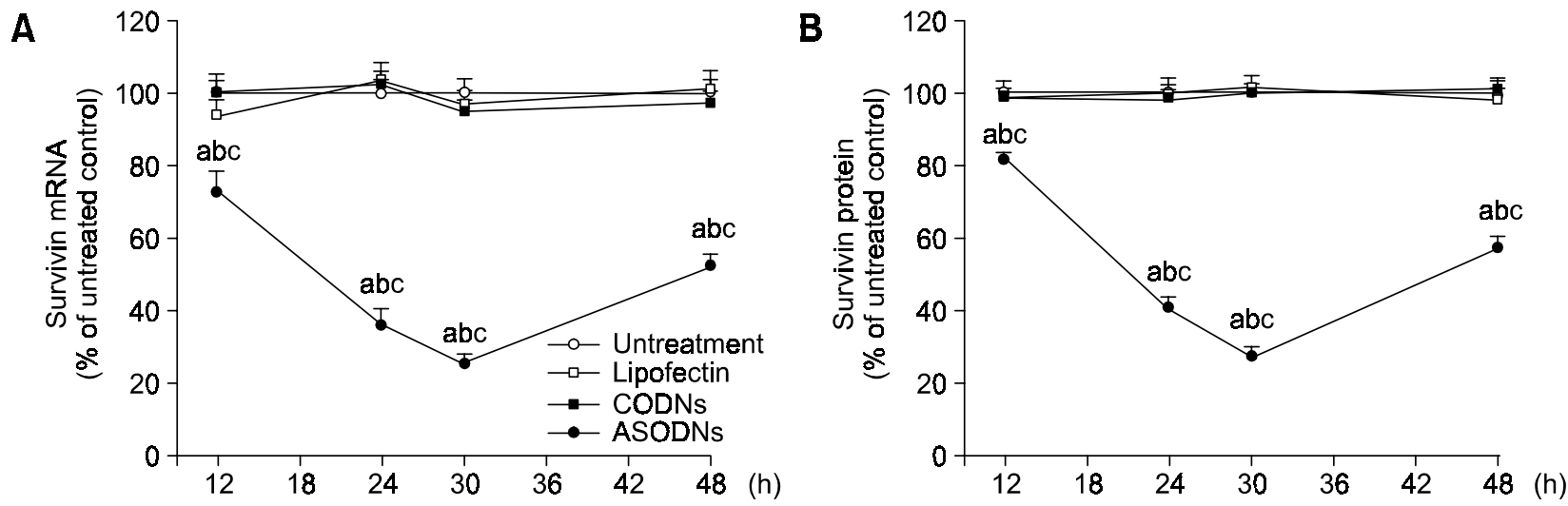

Figure 5. Time course of inhibition of survivin expression by ASODNs in TT cells. Cells are treated with $800 \mathrm{nM}$ ASODNs for $24 \mathrm{~h}$, followed by an additional 6-h culture or longer in fresh F12 medium. The cells were lysed at the indicated time intervals after the start of transfection, relative levels of survivin mRNA and protein were then determined by RT-PCR and Western blot analysis respectively and normalized to those in untreated group which were taken as $100 \%$. Untreated, Lipofectin-treated, and CODNs-treated cells were used as controls. (A) Time course analysis of survivin mRNA levels. (B) Time course analysis of survivin protein levels. Data represent means $\pm \mathrm{SD}\left({ }^{\mathrm{a}} P<0.001\right.$, vs untreatment group; ${ }^{\mathrm{b}} P<0.001$, vs Lipofectin group; ${ }^{C} P<0.001$, vs CODNs group by one-way ANOVA with Bonferroni's post hoc test).

\section{Discussion}

Here we demonstrate for the first time that survivin protein expression is up-regulated in both MTC tissues and human MTC cell line TT relative to negative expression in NT tissues, suggesting it may play an important role in MTC. Survivin has been reported to be highly expressed in several human carcinomas, including lung, breast, colon, and ovary cancer, and scarcely expressed in differentiated normal tissues with the exception of some types of cells, such as basal colonic epithelium endothelial cells and neural stem cells (Ambrosini et al., 1997; Zaffaroni et al., 2005). Furthermore, overexpression of survivin has been demonstrated to correlate with unfavorable prognosis in some tumors (Johnson \& Howerth, 2004).

Papillary, follicular, medullary, and anaplastic carcinoma constitute about $60 \%, 20 \%, 5 \%$ and $10 \%$ of thyroid malignant tumors, respectively. In thyroid neoplasms, Ito et al. found that the positive incidence of suvivin immunoreactivity was $11.1 \%$ (2 of 18 cases), $19.0 \%$ ( 4 of 21 cases), $22.5 \%$ (16 of 71 cases), and $84.2 \%$ (16 of 19 cases) in follicular adenoma, follicular carcinoma, papillary carcinoma, and anaplastic (undifferentiated) carcinoma, respectively, whereas they rarely observed survivin expression in normal thyroid follicules. Through further statistical analyses, they concluded that survivin expression is significantly linked to the dedifferentiation of thyroid carcinoma (Ito et al., 2003). In the present study, we observed a positive incidence of $80 \%$ (8 of 10 cases) in MTC and a high expression of suvivin in TT cells, but in NT, we found a negative incidence of $100 \%$ (10 of 10 cases) consistent with the finding by lto et al. In MTC, we try to reveal the clinicopathologic significance of suvivin expression through its relationships with some clinicopathologic features, but no significant correlation was found between them, suggesting that suvivin expression may be a novel predictor of MTC evolution independent of those conventional clinicopathologic factors. As our preliminary observations on the relationships between suvivin expression and the clinicopathologic features of MTC are based on a very small number of patients, further study involving a large number of patients is necessary to clarify the clinicopathologic significance of suvivin expression in MTC.

In TT cells, we found ASODNs could significantly reduce survivin gene expression at mRNA and protein levels concomitant with a decrease in viability and growth of TT cells in a dose-dependent fashion. Further apoptotic analyses confirmed that the decrease in viability and growth was attributable to apoptotic cell death. As survivin is known to preferentially bind to and inhibit effector caspases, such as caspase-3 and caspase-7 (Tamm et al., 1998), its reduction by ASODNs in TT cells may potentially contribute to the cell apoptosis. In addition, overt inhibitory effects on cell growth and notable induction of apoptosis by ASODNs have also been found in other tumor cell lines (Xia et al., 2002; Cao et al., 2004; Fuessel et al., 2004; Ma et al., 2005). Thus, the survivin-targeted gene therapy using ASODNs may be one of potentially promising alternatives for treatment of tumors.

At present, therapy for MTC is mostly restricted to surgical removal of the tumor tissue, but residual MTC can be detectable in $56 \%$ of patients after 
surgery owing to the early metastatic nature of MTC (Evans et al., 1999; Orlandi et al., 2001). In MTC, objective responses to other forms of therapy such as chemotherapy and radiotherapy are mostly insufficent, fewer than 20\% (Petursson, 1988; Samaan et al., 1988; Wu et al., 1994; Brierley et al., 1996; Vitale et al., 2001). Therefore MTC represents an attractive target for alternative gene therapeutic strategies, of which ASODNs may be considered as one of choices. Moreover, based on the finding of synergic effects of ASODNs in sensitizing cancer cells to chemotherapy and radiation therapy (Olie et al., 2000; Shinohara et al., 2004), ASODNs in combination with other therapeutic strategies may be more powerful in treatment of MTC. In our TT cell line, the IC50 of ASODNs for tumor growth and viability is $723 \mathrm{nM}$, whereas it is $300 \mathrm{nM}$ in a lung carcinoma cell line A549 (Olie et al., 2000), suggesting that lung cancer may be more sensitive to ASODNs as compared with MTC.

In TT cells, through the time course analysis, we found a significant inhibition by $800 \mathrm{nM}$ ASODNs in survivin expression at both mRNA and protein levels, starting within $12 \mathrm{~h}$ and persisting over $48 \mathrm{~h}$ after the start of transfection. In a lung carcinoma cell line A549, Olie et al. observed an obvious reduction by $600 \mathrm{nM}$ ASODNs in suvivin mRNA expression $20 \mathrm{~h}$ after the start of transfection (Olie et al., 2000). In H28 and MS-1 mesothelioma cell lines, Xia et al. detected a noticeable decrease by $500 \mathrm{nM}$ ASODNs in suvivin protein level $17 \mathrm{~h}$ after the start of transfection (Xia et al., 2002). These results indicate an efficient role of ASODNs in inhibition of suvivin expression in various tumor cells.

In conclusion, our data show that: 1) survivin is highly expressed in MTC and a MTC cell line TT, suggesting its important role in MTC, 2) survivin expression is not significantly related to any of the clinicopathologic features of MTC, implying its role in MTC independent of those conventional clinicopathologic factors, and 3) ASODNs could down-regulate suvivin expression, decrease viability and growth, and induce apoptosis in TT cells, indicating its potential value in treatment of MTC.

\section{References}

Abd El-Hameed A. Survivin expression in colorectal adenocarcinoma using tissue microarray. J Egypt Natl Canc Inst 2005;17:42-50

Ambrosini G, Adida C, Altieri DC. A novel anti-apoptosis gene, survivin, expressed in cancer and lymphoma. Nat Med 1997;3:917-21

Ball DW, Baylin SB, de Bustros AC. Medullary thyroid carcinoma. In Thyroid (Braverman LE, Utiger RD, eds), 2001, 930-43, Lippincott Williams \& Wilkins, Philadelphia, PA
Brierley J, Tsang R, Simpson WJ, Gospodarowicz M, Sutcliffe $S$, Panzarella T. Medullary thyroid cancer: analyses of survival and prognostic factors and the role of radiation therapy in local control. Thyroid 1996;6:305-10

Cao C, Mu Y, Hallahan DE, Lu B. XIAP and survivin as therapeutic targets for radiation sensitization in preclinical models of lung cancer. Oncogene 2004;23:7047-52

Evans DB, Fleming JB, Lee JE, Cote G, Gagel RF. The surgical treatment of medullary thyroid carcinoma. Semin Surg Oncol 1999;16:50-63

Fuessel S, Kueppers B, Ning S, Kotzsch M, Kraemer K, Schmidt U, Meye A, Wirth MP. Systematic in vitro evaluation of survivin directed antisense oligodeoxynucleotides in bladder cancer cells. J Urol 2004;171:2471-6

Greene FL, Page DL, Fleming ID, Fritz A, Balch CM, Haller DG, Morrow M. AJCC Cancer Staging Manual, 6th Ed, 2002, Springer-Verlag, New York, NY

Grossman D, McNiff JM, Li F, Altieri DC. Expression of the apoptosis inhibitor, survivin, in nonmelanoma skin cancer and gene targeting in a keratinocyte cell line. Lab Invest 1999; 79:1121-6

Ito Y, Yoshida H, Uruno T, Nakano K, Miya A, Kobayashi K, Yokozawa T, Matsuzuka F, Matsuura N, Kakudo K, Kuma K, Miyauchi A. Survivin expression is significantly linked to the dedifferentiation of thyroid carcinoma. Oncol Rep 2003;10: 1337-40

Johnson ME, Howerth EW. Survivin: a bifunctional inhibitor of apoptosis protein. Vet Pathol 2004;41:599-607

Kato J, Kuwabara Y, Mitani M, Shinoda N, Sato A, Toyama T, Mitsui A, Nishiwaki T, Moriyama S, Kudo J, Fujii Y. Expression of survivin in esophageal cancer: correlation with the prognosis and response to chemotherapy. Int J Cancer 2001;95: 92-5

Kawasaki H, Altieri DC, Lu CD, Toyoda M, Tenjo T, Tanigawa $\mathrm{N}$. Inhibition of apoptosis by survivin predicts shorter survival rates in colorectal cancer. Cancer Res 1998;58:5071-4

Kim HS, Shiraki K, Park SH. Expression of survivin in CIN and invasive squamous cell carcinoma of uterine cervix. Anticancer Res 2002;22:805-8

Kren L, Brazdil J, Hermanova M, Goncharuk VN, Kallakury BV, Kaur P, Ross JS. Prognostic significance of anti-apoptosis proteins survivin and bcl-2 in non-small cell lung carcinomas: a clinicopathologic study of 102 cases. Appl Immunohistochem Mol Morphol 2004;12:44-9

LaCasse EC, Baird S, Korneluk RG, MacKenzie AE. The inhibitors of apoptosis (IAPs) and their emerging role in cancer. Oncogene 1998;17:3247-59

Lee MA, Park GS, Lee HJ, Jung JH, Kang JH, Hong YS, Lee KS, Kim DG, Kim SN. Survivin expression and its clinical significance in pancreatic cancer. BMC Cancer 2005;5:127

Li F, Altieri DC. The cancer antiapoptosis mouse survivin gene: characterization of locus and transcriptional requirements of basal and cell cycle-dependent expression. Cancer Res 1999;59:3143-51

Li F, Ambrosini G, Chu EY, Plescia J, Tognin S, Marchisio PC, 
Altieri DC. Control of apoptosis and mitotic spindle checkpoint by survivin. Nature 1998;396:580-4

Ma X, Wang S, Zhou J, Xing H, Xu G, Wang B, Chen G, Lu YP, Ma D. Induction of apoptosis in human ovarian epithelial cancer cells by antisurvivin oligonucleotides. Oncol Rep 2005; 14 : 275-9

Olie RA, Simoes-Wust AP, Baumann B, Leech SH, Fabbro D, Stahel RA, Zangemeister-Wittke U. A novel antisense oligonucleotide targeting survivin expression induces apoptosis and sensitizes lung cancer cells to chemotherapy. Cancer Res 2000;60:2805-9

Orlandi F, Caraci P, Mussa A, Saggiorato E, Pancani G, Angeli A. Treatment of medullary thyroid carcinoma: an update. Endocr Relat Cancer 2001;8:135-47

Petursson SR. Metastatic medullary thyroid carcinoma. Complete response to combination chemotherapy with dacarbazine and 5-fluorouracil. Cancer 1988;62:1899-903

Samaan NA, Schultz PN, Hickey RC. Medullary thyroid carcinoma: prognosis of familial versus sporadic disease and the role of radiotherapy. J Clin Endocrinol Metab 1988;67:801-5

Shinohara ET, Hallahan DE, Lu B. The use of antisense oligonucleotides in evaluating survivin as a therapeutic target for radiation sensitization in lung cancer. Biol Proced Online 2004;6:250-6

Shinohara ET, Gonzalez A, Massion PP, Chen H, Li M, Freyer AS, Olson SJ, Andersen JJ, Shyr Y, Carbone DP, Johnson DH, Hallahan DE, Lu B. Nuclear survivin predicts recurrence and poor survival in patients with resected nonsmall cell lung carcinoma. Cancer 2005;103:1685-92

Sugawara M, Matsuzuka F, Fukata S, Kuma K, Moatamed F, Haugen BR. Excessive survivin expression in thyroid lymphomas. Hum Pathol 2002;33:524-7

Takeuchi H, Morton DL, Elashoff D, Hoon DS. Survivin expression by metastatic melanoma predicts poor disease outcome in patients receiving adjuvant polyvalent vaccine. Int J Cancer 2005;117:1032-8

Tamm I, Wang Y, Sausville E, Scudiero DA, Vigna N, Oltersdorf T, Reed JC. IAP-family protein survivin inhibits caspase activity and apoptosis induced by Fas (CD95), Bax, caspases, and anticancer drugs. Cancer Res 1998;58:5315-20

Vitale G, Caraglia M, Ciccarelli A, Lupoli G, Abbruzzese A, Tagliaferri P, Lupoli G. Current approaches and perspectives in the therapy of medullary thyroid carcinoma. Cancer 2001; 91:1797-808

Wu LT, Averbuch SD, Ball DW, de Bustros A, Baylin SB, McGuire WP, 3rd. Treatment of advanced medullary thyroid carcinoma with a combination of cyclophosphamide, vincristine, and dacarbazine. Cancer 1994;73:432-6

Xia C, Xu Z, Yuan X, Uematsu K, You L, Li K, Li L, McCormick $\mathrm{F}$, Jablons DM. Induction of apoptosis in mesothelioma cells by antisurvivin oligonucleotides. Mol Cancer Ther 2002;1: 687-94

Zaffaroni N, Pennati M, Daidone MG. Survivin as a target for new anticancer interventions. J Cell Mol Med 2005;9:360-72 